\title{
A participação do público no Wikinews e no Kuro5hin
}

\author{
Marcelo Träsel1 \\ PUC-RS \\ marcelo.trasel@gmail.com
}

\begin{abstract}
Resumo: $O$ artigo apresenta os resultados de uma pesquisa de mestrado focada nas intervenções de colaboradores sobre material jornalístico publicado nos webjornais participativos Wikinews e Kuro5hin. Uma amostra de dez textos foi coletada durante sete semanas, para a criação de um corpus de intervenções que posteriormente foi submetido a uma análise de conteúdo, com o objetivo de verificar se as intervenções tinham caráter predominantemente pluralizante. Os resultados mostram que as intervenções são em sua grande maioria pluralizantes, indicando que o webjornalismo participativo pode trazer contribuições importantes para a democracia.
\end{abstract}

Palavras-chave: Jornalismo, Jornalismo Online, Webjornalismo Participativo, Análise de Conteúdo, Interação

\begin{abstract}
This paper presents the results of a mastership research focused on the interventions of collaborators over journalistic material published in the grassroots news sites Wikinews and Kuro5hin. A sample of ten texts was collected over seven weeks, in order to form a corpus of interventions. This corpus was later submitted to a content analysis, aimed in verifying if the interventions had a predominant pluralizing character. The results show that indeed the interventions are for the most part pluralizing, suggesting that grassroots journalism may bring important contributions to a democratic society.
\end{abstract}

Keywords: Journalism, Online Journalism, Grassroots, Content Analysis, Interaction

1 Jornalista, mestre em Comunicação e Informação pelo PPGCOM/UFRGS, professor da Famecos/PUCRS. Colaborador do Laboratório de Interação Mediada por Computador da Fabico/UFRGS: www.ufrgs.br/limc. 
Résumé: L'article nous présente les résultats d'une recherche faite en cours de Máster concernant les interventions de participants aux matières publiées sur les journaux web Wikinews e Kuro5hin. Un échantillon de dix textes fût rassemblé pendant sept semaines dans l'intention de créer un corpus d'interventions. Ce corpus fût soumis à une analyse de contenu, avec le propos de vérifier si les interventions avaient un aspect pluriel. Les résultats indiquent que les interventions sont, dans sa majorité, plurielles, ce qui démontre que le journalisme web participatif est capable d'apporter des contribuitions importantes à la démocracie.

Mots-cléfs: Journalisme, Journalisme en ligne, Journalisme web participatif, Analyse de contenu, Interaction

Resumen: El artículo presenta los resultados de una investigación de maestría con foco en las intervenciones de colaboradores sobre material periodístico publicado en los periódicos digitales participativos Wikinews y Kuro5hin. Una muestra de diez textos fue colectada durante siete semanas, para la creación de un corpus de intervenciones que más adelante fue sometido en una analice de contenido, con el objetivo de verificar si las intervenciones tenían carácter predominante pluralizante. Los resultados muestran que las intervenciones son en su mayor parte pluralizante, a indicar que lo periodismo digital participativo puede traer contribuciones importantes para la democracia.

Palabras claves: Periodismo, Periodismo Online, Periodismo Digital Participativo, Analice de Contenido, Interacción

O jornalismo está mudando. O desenvolvimento das tecnologias de comunicação e computação permite pela primeira vez, desde o surgimento da sociedade de massa, que os cidadãos ameacem com alguma chance de sucesso o monopólio da "grande mídia" sobre o fluxo de informação. As comportas escancaram-se cada vez mais com o desenvolvimento de tecnologias de comunicação em rede em tempo real, como telefones celulares e redes sem-fio, liberando uma energia expressiva por décadas represada pelos altos custos de produção e circulação dos bens culturais e por políticas de concessão restritivas do espectro eletromagnético e das licenças de impressão. Sob a influência desta onda de publicação amadora, o jornalismo está sendo obrigado a rever seus conceitos, valores e estratégias comerciais. Ainda mais importante, está sendo obrigado a rever seu papel em uma sociedade democrática. 
É bem verdade que apenas uma pequena parcela da população mundial conta com acesso a computadores e à telefonia e nada garante que mesmo essa pequena parcela tenha condições de usá-los de forma construtiva para a democracia. Ainda que tenham acesso à tecnologia, os indivíduos e grupos interessados em distribuir sua produção cultural via Internet estão sujeitos a fatores históricos, econômicos e sociais que não podem ser desprezados. Apesar de reconhecer sua existência, não é possível no presente trabalho discutir o problema das condições de acesso e uso das redes telemáticas. Aqui, o foco será dirigido aos grupos que de uma forma ou de outra transpuseram as barreiras de acesso à Internet, mais especificamente à World Wide Web, e já estão fazendo uso dela para publicar material multimídia.

Os webjornais têm cada vez mais cortejado a participação dos leitores², ainda que de forma tímida, por meio de correio eletrônico, boletins, fóruns, enquetes e outros recursos. Em geral, todavia, mantendo o controle da publicação nas mãos de uma equipe de jornalistas profissionais, com formação específica ou não, dependendo do contexto legal do país onde a empresa tem sede. Alguns webjornais abriram espaços para que os leitores comentem as matérias, como o alemão Die Zeit, ou criaram blogs da redação que contam com espaço para comentários, como o britânico The Guardian 4 ou o brasileiro Globo Online5. Outros, como o Los Angeles Times $^{6}$, chegaram ao extremo de abrir seus editoriais para intervenção direta do público - suspendendo a iniciativa em pouco tempo, devido à profusão de imagens pornográficas publicadas pelos colaboradores7. O sul-coreano OhmyNews ${ }^{8}$ foi um dos primeiros a se basear desde a concepção na interação entre leitores e jornalistas

\footnotetext{
2 Seguindo proposta de SANTAELLA (2004, p.17), os websites serão considerados como objeto de leitura, a despeito de serem constituídos por linguagem escrita, imagem e áudio, isto é, serem peças multimidiáticas. Desta forma, os internautas que acessam tais websites serão designados leitores: “...desde os livros ilustrados e, depois, com os jornais e revistas, o ato de ler passou a não se restringir apenas à decifração de letras, mas veio também incorporando, cada vez mais, as relações entre palavra e imagem, desenho e tamanho de tipos gráficos, texto e diagramação."

3 http://www.zeit.de.

4 http://www.guardian.co.uk.

5 http://oglobo.globo.com.

$6 \mathrm{http}: / /$ www.latimes.com.

7 MSNBC. Los Angeles Times suspends "Wikitorials". 21/6/2005. Disponível em:

http://www.msnbc.msn.com/id/8300420/. Último acesso em: 09/01/2007.

8 http://english.ohmynews.com.
} 
(BRAMBILLA, 2006). Sob a palavra-de-ordem "todo cidadão é um repórter", o fundador Oh Yeon Ho permitiu que qualquer cidadão enviasse matérias que são editadas e publicadas pela equipe de jornalistas do OhmyNews, em troca de uma pequena quantia em dinheiro.

Uma outra frente de participação cidadã na mídia online é a publicação sem supervisão prévia ou posterior por jornalistas profissionais. O grande expoente deste tipo de participação são os weblogs, ou blogs, páginas da World Wide Web atualizadas com freqüência, com registros datados e ordenados por ordem cronológica, aparecendo os mais recentes no topo (BLOOD, 2002). Conforme o relatório Bloggers: a portrait of the Internets new storytellers (PEW, 2006), 12 milhões de americanos adultos dizem manter um blog e 57 milhões lêem blogs. O uso mais comum é a publicação de diatribes e relatos sobre o cotidiano, mas muitos blogueiros se dedicam a disseminar informações altamente especializadas, reportagens ou análises e críticas das notícias publicadas pela imprensa:

Os blogs estão filtrando as notícias, detalhando o cotidiano de vidas e oferecendo respostas editoriais para os eventos do dia. Para muitas pessoas, um weblog é um palanque do qual podem proclamar seus pontos de vista, potencialmente influenciando muito mais pessoas do que poderiam em seu dia-a-dia (BLOOD, 2002, p.X) 9 .

As ferramentas que permitem a qualquer um criar um blog sem a necessidade de ser um especialista em informática deram a virtualmente todo cidadão com acesso à Web a possibilidade de se expressar. Outras ferramentas que permitiam a publicação na Web sem a necessidade de saber programar existiam antes - como os wikis ${ }^{10}$, por exemplo -, mas nenhuma se tornou tão popular. Os blogs se tornaram uma fonte de informação alternativa quando os webjornais ficaram inacessíveis devido ao imenso tráfego de internautas em busca de notícias sobre o

9 "Blogs are filtering the news, detailing daily lives, and providing editorial responses to the events of the day. For many people, a weblog is a soapbox from which they can proclaim their views, potentially influencing many more people than they can in their everyday lives." Tradução livre.

10 Wikis são programas instalados num servidor, acessíveis através de um navegador normal, que permitem aos usuários a criação e publicação conjunta de conteúdo em páginas da Web. Em geral, qualquer um pode editar o conteúdo, inclusive as contribuições de outros usuários. A maioria dos wikis também oferece um histórico de modificações, que permite a reversão para versões anteriores. Disponível em: http://pt.wikipedia.org/wiki/Wiki. Último acesso em: 14 de julho de 2007. 
ataque às Torres Gêmeas. Do Iraque, o blogueiro Salam Pax $^{11}$ publicou a visão dos civis locais sobre a segunda invasão americana ao país. Em 2004, o pré-candidato democrata Howard Dean entrou efetivamente na disputa com John Kerry ao levantar milhões de dólares em pequenas doações através de seu blog de campanha (GILLMOR, 2004).

Estes eventos marcam o florescimento do jornalismo participativo na Web, ou webjornalismo participativo, definido por PRIMO e TRÄSEL (2006, p.9) como "práticas desenvolvidas em seções ou na totalidade de um periódico noticioso na Web, onde a fronteira entre produção e leitura não pode ser claramente demarcada ou não existe”. O termo refere-se àqueles webjornais em que o público pode intervir sobre o conteúdo publicado, seja enviando seu próprio material jornalístico ${ }^{12}$, seja reescrevendo textos, fazendo comentários sobre e debatendo a partir do material jornalístico publicado por outros colaboradores. Blogs que se dedicam a debater os fatos do dia ou publicar reportagens e notícias e webjornais como o OhmyNews são exemplos de webjornalismo participativo.

Não é mais questão de se indivíduos sem educação formal ou licença profissional vão publicar sua própria produção e influenciar a esfera midiática, mas de quanto e como. Os jornalistas terão de conviver mais cedo ou mais tarde com o fato de que serão pautados pelas pessoas que antes ocupavam a posição de simples consumidores de notícias no imaginário das redações. Doravante, sempre haverá um especialista em determinado assunto com disposição para apontar erros factuais ou mesmo casos de má-fé usando as ferramentas do webjornalismo participativo. GILLMOR (2004) descreve como o que chama de "ex-audiência" está usando blogs, correio eletrônico, chats, fóruns e outros veículos de comunicação via Internet para dar sua própria versão dos acontecimentos e, sobretudo, contestar informações publicadas pela imprensa.

11 Seu weblog, interrompido em 2004, está no endereço http://www.dear_raed.blogspot.com. $12 \mathrm{O}$ termo será usado neste trabalho para se referir aos doze gêneros jornalísticos propostos por MELO (2003): nota, notícia, reportagem e entrevista, dentro da categoria jornalismo informativo; e editorial, comentário, artigo, resenha, coluna, crônica, caricatura e carta, na categoria jornalismo opinativo. Prefere-se não usar o termo notícia porque no Brasil este designa um tipo muito específico de texto narrativo, calcado no uso do modelo da pirâmide invertida (LAGE, 1993). 
Antes mera consumidora de notícias, a audiência está aprendendo como conseguir informação melhor e mais oportuna. Também está aprendendo como se juntar ao processo jornalístico, ajudando a criar uma enorme conversação e, em alguns casos, fazendo um trabalho melhor que o dos profissionais (p.XIV) ${ }^{13}$.

É certo que a participação da "ex-audiência” no processo jornalístico não é boa em si mesma e merece um exame profundo. Na verdade, há bastante ceticismo quanto às vantagens que a participação do público possa trazer para o jornalismo, especialmente entre os jornalistas. Dado que o webjornalismo participativo existe, que indivíduos isolados e grupos de interesse estão produzindo material jornalístico e publicando-o na Web, com ou sem supervisão de profissionais da imprensa, é importante analisá-lo sem preconceitos, procurando destacar tanto as promessas quanto as ameaças que esse fenômeno traz para o futuro do jornalismo e da democracia.

Este trabalho apresenta uma parte dos resultados da pesquisa realizada durante meu curso de mestrado, que gerou a dissertação $A$ pluralização no webjornalismo participativo: uma análise das intervenções no Wikinews e no Kuro5hin (TRÄSEL, 2007). O objetivo principal desta pesquisa foi verificar se a participação de "leigos" no webjornalismo resulta em uma proporção significativa de contribuições preocupadas em atender a critérios e valores jornalísticos e de maneira geral expandir o debate democrático, ou apenas em interferências mais preocupadas com a gramática e ortografia, estilo, frivolidades e mesmo bate-bocas inúteis. Em outras palavras, nas intervenções feitas pelos colaboradores em webjornais participativos, predomina o caráter pluralizante, ou o caráter formal/disruptivo? Para responder a essa questão, foram selecionados para análise dois webjornais participativos em inglês, o Wikinews e o Kuro5hin, que serão apresentados brevemente a seguir.

\section{Wikinews}

Wikis são sistemas cuja característica mais notável é permitir a edição de páginas da Web por qualquer internauta, sem o conhecimento de HTML ou qualquer

13 "Once mere consumers of news, the audience is learning how to get a better, timelier
report. It's also learning how to join the process of journalism, helping to create a massive
conversation and, in some cases, doing a better job than the professionals." Tradução livre. 
linguagem de programação e usando apenas um navegador comum. Além disso, todo link introduzido em um texto remete a uma página dentro do próprio wiki, ou cria uma nova página, caso aquele título ainda não exista. Wikis oferecem também um histórico de modificações para cada página, de modo que se possa reverter erros ou atos de vandalismo. O Wikinews $(W N)^{14}$ é o projeto de uma agência de notícias aberta e livre, baseada em um sistema wiki e produzida por uma comunidade de colaboradores.

Ao entrar na página principal do $W N$, o navegante se depara com uma manchete, seguida abaixo por outras matérias de importância. Em geral, há fotos. Um menu no canto superior direito oferece links para as listas de notícias em diferentes línguas. Acima da manchete, há uma caixa de texto com apontadores destinados às "últimas notícias", a páginas sobre como participar, iniciar um artigo, à "redação"15 (newsroom) e a versões em áudio e impressas, bem como outros serviços. Na coluna esquerda há um menu de navegação.

No topo de cada página do $W N$, abas oferecem as opções de participar de uma discussão aberta a respeito da primeira página com outros colaboradores, exibir o código fonte e o histórico de modificações. Não é necessário se cadastrar para fazêlo. Se o leitor clicar em "editar esta página” (edit this page), será apresentada uma plataforma com o código do texto, que utiliza uma sintaxe simplificada. Há também uma barra de tarefas que permite introduzir a sintaxe específica sem a necessidade de memorizá-la. O leitor então pode fazer as mudanças que achar necessárias no texto e depois republicá-lo, clicando em "salvar página”. A mudança entra no ar automaticamente.

\footnotetext{
14 http://en.wikinews.org/wiki/Main_Page. 15 Trata-se de uma página onde os colaboradores podem checar quais artigos estão sendo escritos no momento e como podem colaborar para seu desenvolvimento, bem como contatar outros membros da "comunidade Wikinews" e acessar recursos para a redação de suas colaborações. Disponível em: http://en.wikinews.org/wiki/Wikinews:Newsroom. Último acesso: $14 / 05 / 2007$.
} 


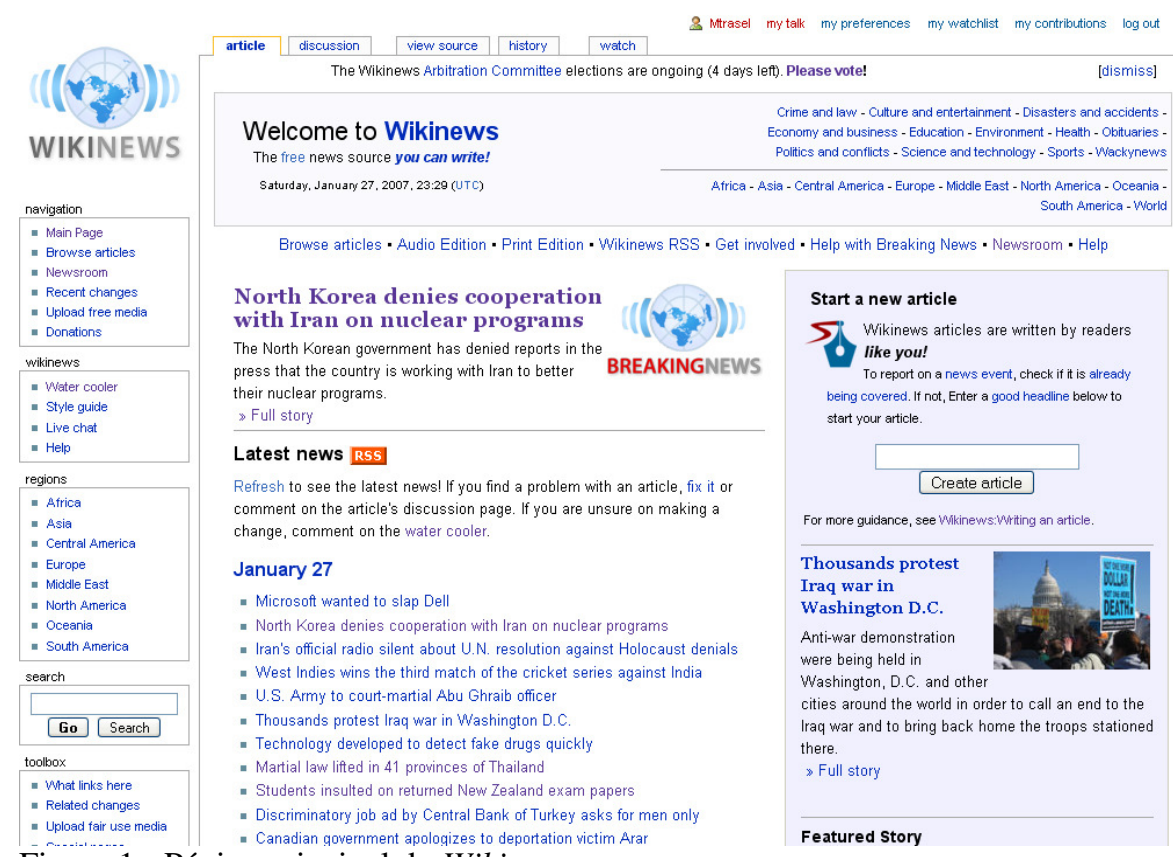

Figura 1- Página principal do Wikinews

Fonte: http://en.wikinews.org. Acesso: 21/01/2007

De acordo com o guia do $W N^{16}$, as notícias publicadas devem ser: a) focadas em um único assunto; b) escritas de um ponto de vista neutro; c) factuais; d) relevantes; e) globais e locais; e f) colaborativas. Editoriais, press releases e artigos científicos não são aceitos. "Uma matéria do Wikinews não tem um repórter como seu autor, o mundo está convidado a participar e escrever, editar e reescrever cada artigo para melhorar seu conteúdo" ${ }^{17}$. Não há controle prévio sobre a publicação de matérias, espera-se que a própria comunidade de colaboradores corrija erros e elimine os conteúdos que infringem as regras editoriais.

16 Disponível em: http://en.wikinews.org/wiki/Wikinews:What_Wikinews_is. Acesso: $10 / 02 / 2007$.

17 "A Wikinews story does not have one reporter as its author, the world is invited to join in and write, edit and rewrite each article to improve its content.” Tradução livre. Disponível em: http://en.wikinews.org/wiki/Wikinews:What_Wikinews_is. Acesso: 10/02/2007. 


\section{(e) compós}

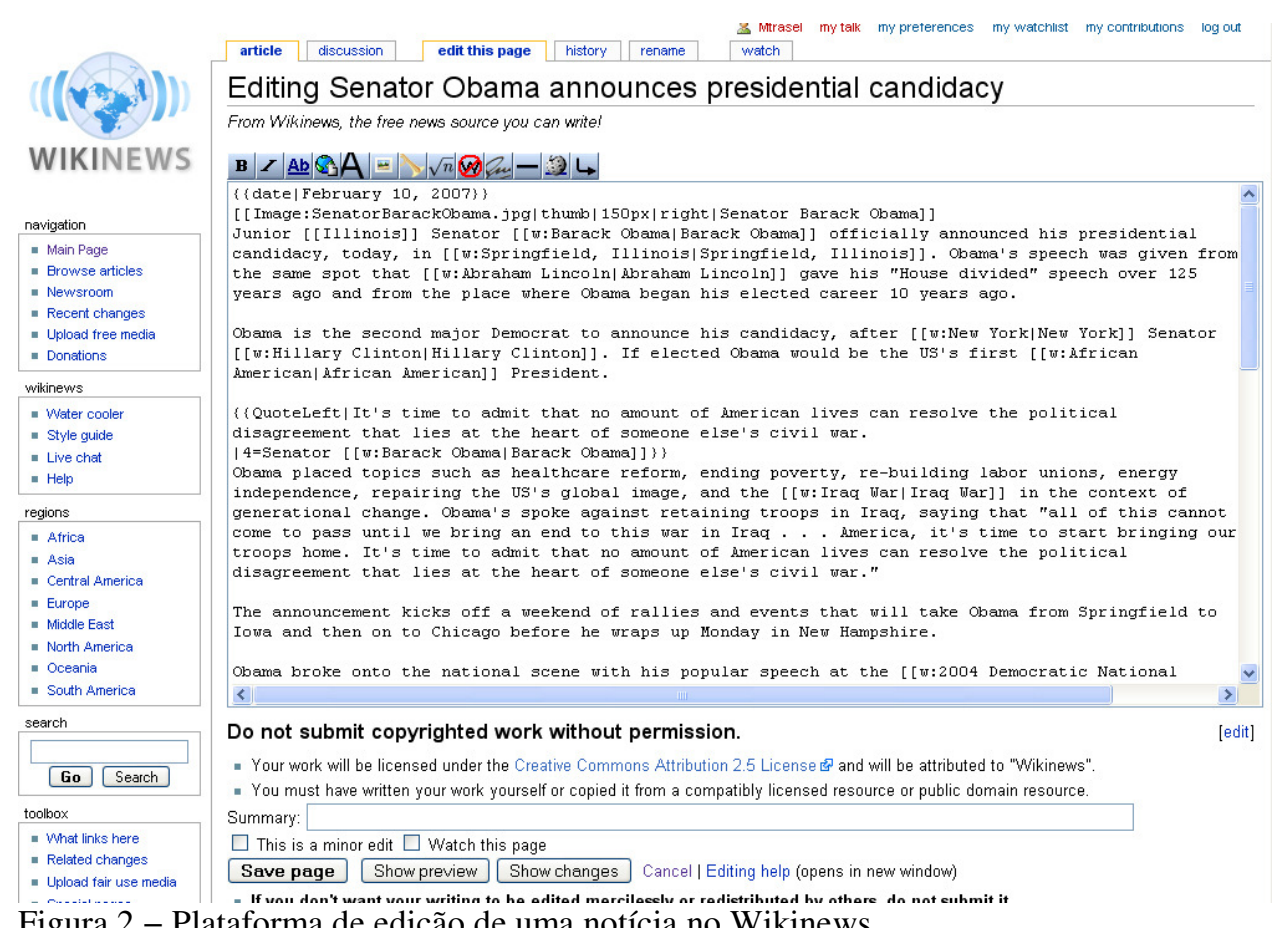

Figura 2 - Plataforma de edição de uma notícia no Wikinews

Fonte: http://en.wikinews.org. Acesso: 11/02/2007

Um histórico de modificações acompanha cada matéria do $W N$, permitindo que o texto seja revertido a uma versão anterior em caso de erro ou vandalismo. Após uma semana, em geral, um colaborador com status de administrador do sistema fecha a matéria para edição, se ela for considerada completa pelos envolvidos em sua preparação.

\section{KURO5HIN}

O Kuro5hin $\left(K_{5}\right)^{18}$ funciona de maneira bastante diferente do $W N$, embora também seja baseado no princípio da colaboração entre repórteres amadores. O K5 foi aberto pelo programador Rusty Foster em 21 de dezembro de 1999. O título é um apelido usado na Web pelo próprio Rusty, uma brincadeira com seu nome, pois Kuro5hin é uma corruptela de corrosion, ou “corrosão”, e Rusty é relativo a rust, ou “ferrugem”. O “5” substituindo um "S" é homenagem ao personagem Da5id"19, do livro Snow Crash, de Neal Stephenson.

$18 \mathrm{http}: / /$ www.kuro5hin.org.

19 Trata-se de um tipo de escrita conhecido como leet script (também grafado l33t ou 1337), típico das subculturas da informática, usada principalmente entre programadores, hackers e jogadores de videogames. $\mathrm{O}$ termo é uma corruptela baseada na pronúncia inglesa da palavra 
Em termos de conteúdo, há uma clara opção em favor das discussões que ocorrem nos fóruns relacionados a cada matéria, mais do que em publicar notícias. "Damos bastante preferência a propostas que expressem um argumento ou ponto de vista sobre a matéria e encorajem a discussão ou o debate." ${ }^{\circ 0}$ Os artigos são freqüentemente escritos em primeira pessoa e raramente partem de uma notícia publicada em outro webjornal ou site.

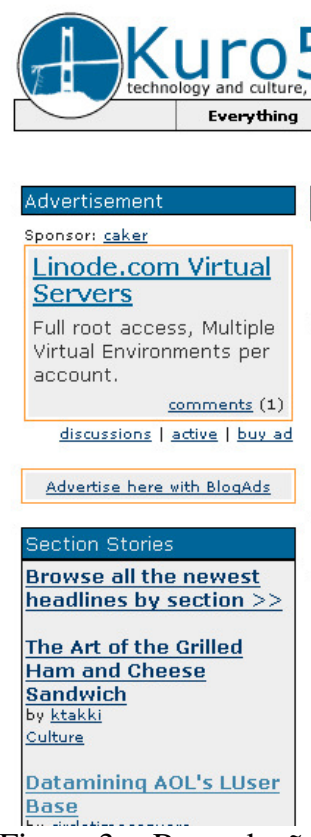

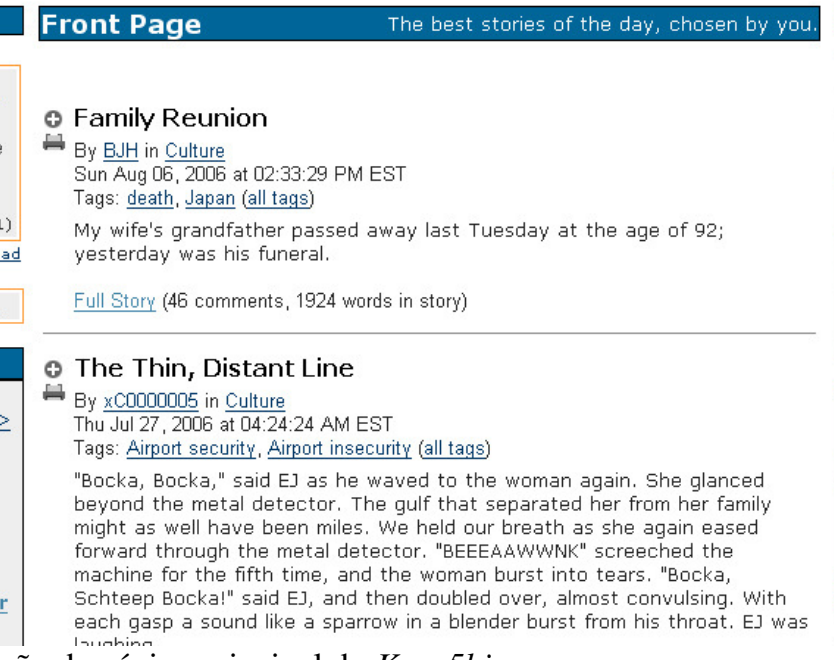

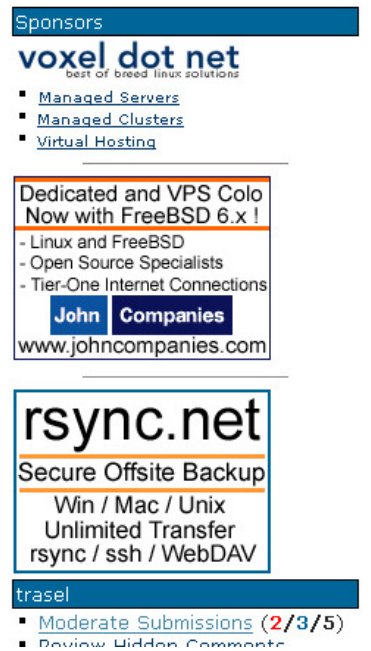

Figura 3 - Reprodução da página principal do Kuro5hin

Fonte: http://www.kuro5hin.org. Acesso em: 16/8/2006

Na coluna central da página principal aparecem dez matérias que tenham sido escolhidas para a posição. Elas não são necessariamente recentes. No dia 6 de agosto de 2006, por exemplo, a primeira posição era ocupada por um artigo em primeira pessoa sobre um funeral japonês ${ }^{21}$, publicado naquele dia, enquanto o artigo

\footnotetext{
"elite" e pretende indicar que quem usa esse tipo de grafia é um usuário de computadores experiente.

20 "We very much prefer article submissions that express an argument or point of view about the article, and encourage discussion or debate". Tradução livre. Disponível em: http://www.kuro5hin.org/special/faq. Último acesso em: 5/8/2006.

21 BJH. Family reunion. Kuro5hin, 6/8/2006. Disponível em: http://www.kuro5hin.org/story/2006/8/4/17244/24684. Último acesso em: 15/8/2006.
} 
em última posição, uma receita do prato indiano chamado vindaloo ${ }^{22}$, fora publicado no dia 22 de junho, mais de um mês antes.

O K5 é dividido em 12 seções: diaries (diários), que funciona como um blog para digressões pessoais, cujo subtítulo é "se você não tem nada a dizer, diga aqui"; technology (tecnologia), para matérias a respeito de equipamentos e programas; science (ciência), para artigos relacionados a pesquisa e estudos; culture (cultura), cuja descrição é "o mundo em que vivemos: discutam”; politics (política); media (mídia), voltado a comentários sobre noticiários e entretenimento; Internet, com foco no aspecto social, não no tecnológico; $O p-E d$ (editorial), para artigos de opinião; fiction (ficção), para publicação e discussão de textos narrativos e poéticos; meta, onde são publicados os artigos sobre o próprio K5; MLP ou Mindless Link Propagation (propagação impensada de links), para notas com sugestões de sites; e finalmente news (notícias), onde os coladoradores podem publicar informação atual. Um aviso na descrição desta seção define melhor a diferença de matérias com links e o que a comunidade critica como "propagação impensada" dos mesmos: "Aqui é onde VOCÊ relata as notícias, chega às suas próprias conclusões, adicionando links como forma de providenciar informação suplementar (em oposição à MLP onde o link É a informação)"23.

Qualquer internauta pode se cadastrar como colaborador do $K_{5}$, bastando escolher um nome de usuário (username) e indicar um endereço válido de correio eletrônico. Após esse breve trâmite, pode submeter matérias à votação da comunidade. No topo de cada página há o apontador submit story (submeter matéria), clicando-se no qual se é dirigido a um formulário. Um texto pede que o colaborador leia ao menos uma vez as diretrizes editoriais e oferece alguns lembretes, como por exemplo não deixar de escolher um tópico, checar todos os endereços eletrônicos para os quais se apontou, e checar os fatos. Também avisa que a equipe editorial - colaboradores antigos com status de administradores do sistema - guarda o direito de corrigir erros gramaticais e de estilo, mas sempre procurando manter o

22 TROLLAXOR. Vindaloo a l'Agni. Kuro5hin, 22/6/2006. Disponível em: http://www.kuro5hin.org/story/2006/6/20/141135/408. Último acesso em: 15/8/2006. 23 "This is where YOU report the news, come up with your own conclusions, adding links as a way of providing supplementing information (as opposed to MLP where the link IS the information).” Tradução livre. Disponível em: http://www.kuro5hin.org/special/faq. Último acesso em: 5/8/2006. 
sentido original. As diretrizes editoriais se limitam a explicar os aspectos técnicos da publicação, com poucos conselhos a respeito de estilo, como escolher um título curto e atraente, ou tentar adequar o máximo possível o assunto à seção escolhida.

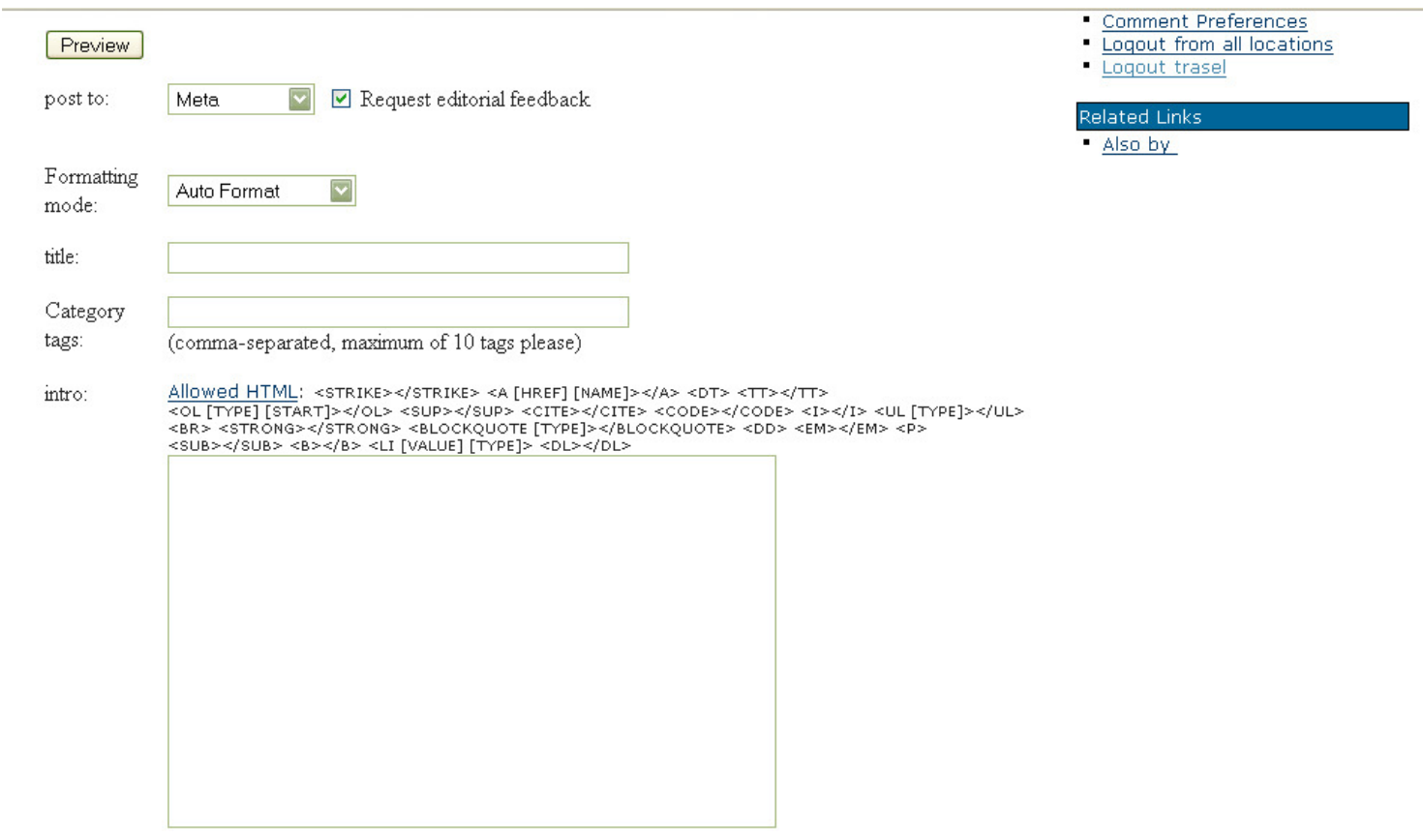

Figura 4 - Formulário para o envio de matérias para a lista de edição ou votação Fonte: http://www.kuro5hin.org. Acesso em: 15/8/2006

O formulário oferece os campos post to (publicar em), em que se escolhe a seção; formatting mode (modo de formatação), que pode ser automático, HTML ou texto simples; título; category tags, ou "etiquetas" de categorias para recuperação por assunto; introdução, ou seja, o trecho de um ou dois parágrafos que aparece como resumo ou introdução do texto; corpo do texto; e enquete, que não é obrigatória.

Ao entrar no sistema, o colaborador também ganha o direito de votar em propostas de outros internautas e a moderar comentários. Seguindo o link moderate submissions uma lista de propostas em votação é mostrada e, ao clicar-se em algum dos títulos, pode-se ler o texto completo. Ao final, um seletor oferece as opções post it to the front page! (publicar na primeira página), post it to the section page only (publicar apenas na seção), abstain! (abster-se), e dump it! (eliminar). A cada opção é atribuído um valor numérico. Os pontos são somados e, quando atingem um certo 
nível, a matéria é recusada ou aceita. Em geral o patamar de publicação é 70 pontos, enquanto o patamar de recusa é de -20 pontos. O colaborador também pode fazer comentários sobre o texto, nos mesmos moldes dos comentários feitos na zona aberta do $K 5$, bem como avaliar os comentários feitos por outros colaboradores. A avaliação é feita por meio de um seletor, com as opções hide (esconder), discourage (desencorajar), neutral (neutro) e encourage (encorajar). Pode-se visualizar todos os comentários, ou ler conforme a classificação. Os leitores não cadastrados também têm à sua disposição estas opções de visualização dos comentários, mas não podem votar em sua qualidade.

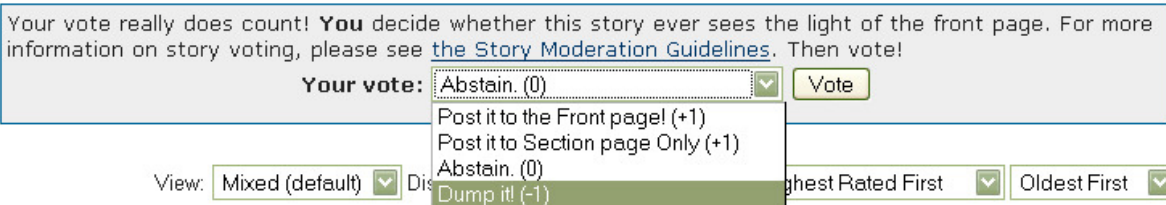

Travelling by Train in North America | 9 comments (4 topical, 5 editorial, 0 hidden) | Post A Comment

Figura 5 - Formulário e opções de voto em matéria enviadas por colaborador Fonte: http://www.kuro5hin.org. Acesso em: 16/8/2006

O objetivo de todos estes níveis de avaliação é, por um lado, permitir o autogerenciamento da comunidade de colaboradores e da publicação de textos e, por outro lado, impedir que vândalos soterrem os comentários relevantes com intervenções desnecessárias ou ataques gratuitos. O sistema tem ainda a vantagem de facilitar a filtragem da informação, pois o leitor pode contar com avaliações de dezenas de outros leitores como forma de aferição da qualidade.

\section{Procedimentos metodológicos}

O método usado nesta pesquisa foi a análise de conteúdo. A escolha foi feita esperando que as técnicas deste método permitissem evidenciar as tendências predominantes nas intervenções feitas pelos colaboradores dos webjornais participativos. A hipótese a testar era que os colaboradores produzem uma quantidade predominante de intervenções que ampliam os aspectos jornalísticos dos textos iniciais a que se referem, resultando em uma multiplicação das perspectivas sobre os temas em questão. Este tipo de intervenção foi denominado "pluralizante", e incluiu as seguintes subcategorias: edição, dados, fontes, valor-notícia, multimídia, links e argumentação. As outras intervenções encontradas foram reunidas sob a 
categoria "formais/disruptivas" e incluíram as subcategorias ortografia/gramática, formatação, disrupção e spam. Além disso, foi criada a categoria "outros", para aquelas intervenções que não se enquadrassem em nenhum outro tipo.

Os dados foram coletados no $W N$ e no $K 5$ durante sete dias em sete semanas alternadas, totalizando dez textos iniciais e intervenções a eles relacionadas. Considerou-se "texto inicial" a primeira versão de uma matéria publicada no $W N$, sobre a qual os colaboradores irão trabalhar diretamente, e a proposta de matéria enviada para a fila de edição no $K_{5}$, à qual serão atreladas sugestões de mudanças e opiniões sobre o conteúdo. O período de coleta começou na terça-feira, dia 17 de outubro de 2006. A coleta seguinte ocorreu na quarta-feira, 25 de outubro de 2006 e assim por diante até o último dia, 3 de dezembro, uma segunda-feira. Todas foram feitas na mesma faixa de horário, entre 13:30 e 14:00. As páginas foram abertas em diferentes janelas do navegador e depois arquivadas em formato HTML e em texto. No $K_{5}$, foram selecionados os textos que estivessem em último lugar na fila de edição. Quando não havia texto algum na fila de edição, não se coletou material. No caso do $W N$, foram selecionados os textos que estivessem em último lugar na lista de últimas notícias na página principal. Ao todo, foram coletados três textos no K5 e sete textos no $W N$. Em quatro ocasiões, não havia nenhuma proposta de matéria na fila de edição do $K_{5}$ no momento da coleta.

Cada um dos textos coletados recebeu um código. No caso do $W N$, tratou-se da letra W acompanhada de números em ordem cronológica crescente de coleta (W1, W2 etc.). As intervenções aos textos receberam um código alfanumérico tendo como critério a ordem crescente desde a primeira intervenção ao primeiro texto até a última intervenção ao último texto (IW1, IW2... IW45). O mesmo sistema foi usado no $K_{5}$, com as letras $\mathrm{K}$ (K1, K2...) e IK (IK1, IK2... IK63). Posteriormente, essas unidades foram tabuladas conforme um roteiro de análise. Os dados resultantes são interpretados a seguir.

\section{Resultados da análise}

O material jornalístico coletado nos dois webjornais participativos resultou em um corpus composto por 107 intervenções, sendo 46 delas referentes ao $W N$ e 61 ao K5. Trata-se de uma distribuição interessante, já que foram coletados sete textos 
no $W N$ e apenas três no $K_{5}$. Ainda que menos representado na amostra, o $K_{5}$ apresentou mais ocorrências de intervenção sobre os textos iniciais, o que sugere um nível maior de participação em números absolutos. Esse dado pode ser explicado pela própria política editorial do $K_{5}$, que favorece o debate a respeito dos fatos apresentados no texto inicial. Assim, os colaboradores continuam intervindo, mesmo quando já foram realizados todos os reparos necessários para enquadrar o texto nos padrões esperados (ortografia e estilo corretos, política editorial, atribuição de fontes, links para material em outros sites etc.). No $W N$, por outro lado, o comentário a respeito dos fatos narrados nos textos é desencorajado, de modo que, quando todas as correções e acréscimos que visam colocar o texto dentro dos padrões editoriais são feitos, não há mais motivo para a intervenção. $O$ fato de nenhuma intervenção de caráter argumentativo ou disruptivo ter sido identificada no na análise do $W N$ corrobora essa conclusão.

As 46 intervenções feitas aos textos do $W N$ resultaram em 35 unidades de análise categorizadas como pluralizantes e 18 unidades categorizadas como unidades formais/disruptivas. A discrepância entre o número de intervenções e o número de unidades de análise codificadas se deve ao fato de que algumas intervenções forneceram mais de uma unidade. Em uma intervenção feita às 21:51 do dia 15 de outubro de 2006 à matéria "Friday the 13 Buffalo, New York snow storm in pictures"24, por exemplo, o colaborador DragonFire1024 acrescentou uma nova fonte, o jornal Lockport Union-Sun \& Journal, e corrigiu dados no lead, como o número de pessoas sem luz (passou de 340 mil para 300 mil) e a inclusão do Estado de Pensylvannia entre os atingidos, gerando as unidades "fonte" e "dados". O mesmo critério de codificação e contagem das unidades foi usado no K5. Em um comentário que discute um texto de MotorMachineMercenary sobre seriados de televisão ${ }^{25}$, o colaborador OnDemand fornece dados sobre o serviço de TV a cabo Comcast através de seu próprio depoimento e depois segue argumentando sobre as diferenças entre o modelo de negócios da TV por assinatura e da radiodifusão, para concluir que alguns

\footnotetext{
24 Disponível em:

http://en.wikinews.org/wiki/\%22Friday_the_13\%22_Buffalo\%2C_New_York_snow_storm _in_pictures. Último acesso em: 14 de julho de 2007.

25 MotorMachineMercenary. The rise of the TV serial. Kuro5hin, 27 de out/2006. Disponível em: http://www.kuro5hin.org/story/2006/10/24/211246/67. Último acesso em: 14 de julho de 2007.
} 
tipos de séries são economicamente inviáveis na TV aberta. Considerou-se que nesta intervenção estão presentes duas unidades de análise, "dados" e "argumentação". As 61 intervenções feitas ao $K 5$ resultaram em 54 unidades de análise categorizadas como pluralizanetes e 13 como unidades formais/disruptivas, conforme a tabela abaixo.

Tabela 1 - Distribuição de unidades por categoria em números absolutos e proporcionais

\begin{tabular}{|c|c|c|c|c|c|c|c|}
\hline & Pluralizantes & $\%$ & Formais/Disruptivas & $\%$ & Outros & $\%$ & Total \\
\hline Wikinews & 35 & 63,6 & 18 & 32,7 & 2 & 3,7 & 55 \\
\hline Kuro5hin & 54 & 76,8 & 13 & 18,8 & 2 & 2,9 & 69 \\
\hline Total & 89 & 73,2 & 31 & 22,7 & 4 & 4,1 & 124 \\
\hline
\end{tabular}

A tabela 1 mostra em números absolutos e em porcentagem a distribuição das unidades segundo as categorias de análise. Entre as 107 intervenções coletadas foram identificadas 124 unidades de análise, das quais a maioria, 89, foram consideradas pluralizantes, e 31 formais/disruptivas. Em termos proporcionais, houve predominância significativa das unidades pluralizantes (73,2\%). O webjornal participativo $K_{5}$ apresentou mais unidades pluralizantes em relação ao $W N$, tanto em termos absolutos quanto proporcionais. Houve 54 unidades pluralizantes nas intervenções do $K_{5}$, representando $76,8 \%$ do total de unidades. No caso do $W N$, as unidades pluralizantes representam 63,6\% do total. Apesar da leve vantagem do $K_{5}$, trata-se de um resultado bastante semelhante, que sugere forte orientação dos colaboradores dos dois webjornais participativos para interferir nas questões jornalísticas do texto.

Os dados referentes ao número de colaboradores que intervieram em cada matéria indicam que os indivíduos costumam acompanhar o desenvolvimento dos textos em que tomam parte. As figuras 6 e 7 mostram que tanto no $K_{5}$ quanto no $W N$ 
a quantidade de colaboradores em determinada matéria costuma ser menor do que a quantidade de intervenções. A correlação entre os dois indicadores é de um para dois, ou seja, cada colaborador tende a retornar em média duas vezes aos textos dos quais toma parte.

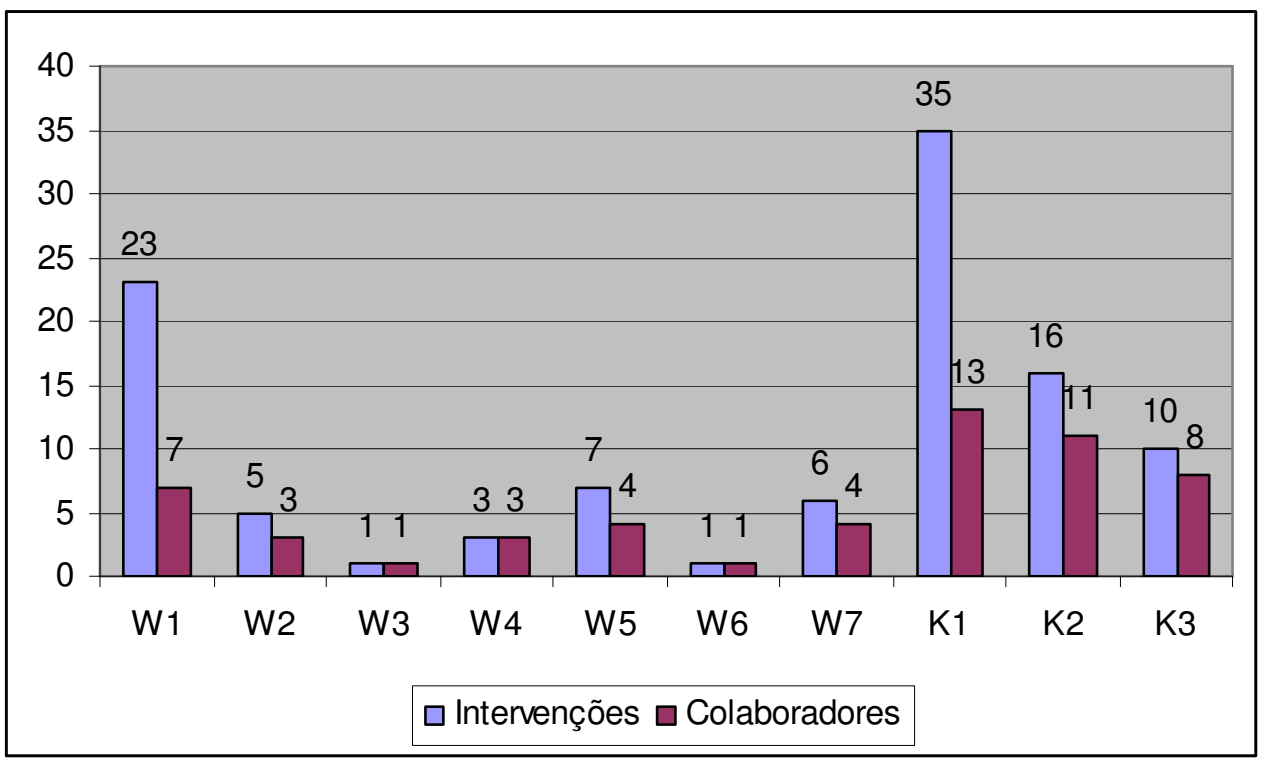

Figura 6 - Gráfico comparativo do número de intervenções e número de colaboradores

Isto significa que em geral os indivíduos que intervém no material jornalístico publicado por estes dois webjornais participativos não são colaboradores acidentais, mas sim colaboradores que acompanham constantemente o processo de trabalho. Este também é um indicativo que sugere a formação de redes sociais de colaboradores em torno dos webjornais participativos. A figura 7 mostra a diferença entre o número de intervenções total em cada webjornal participativo e o número global de colaboradores identificados na amostra. 


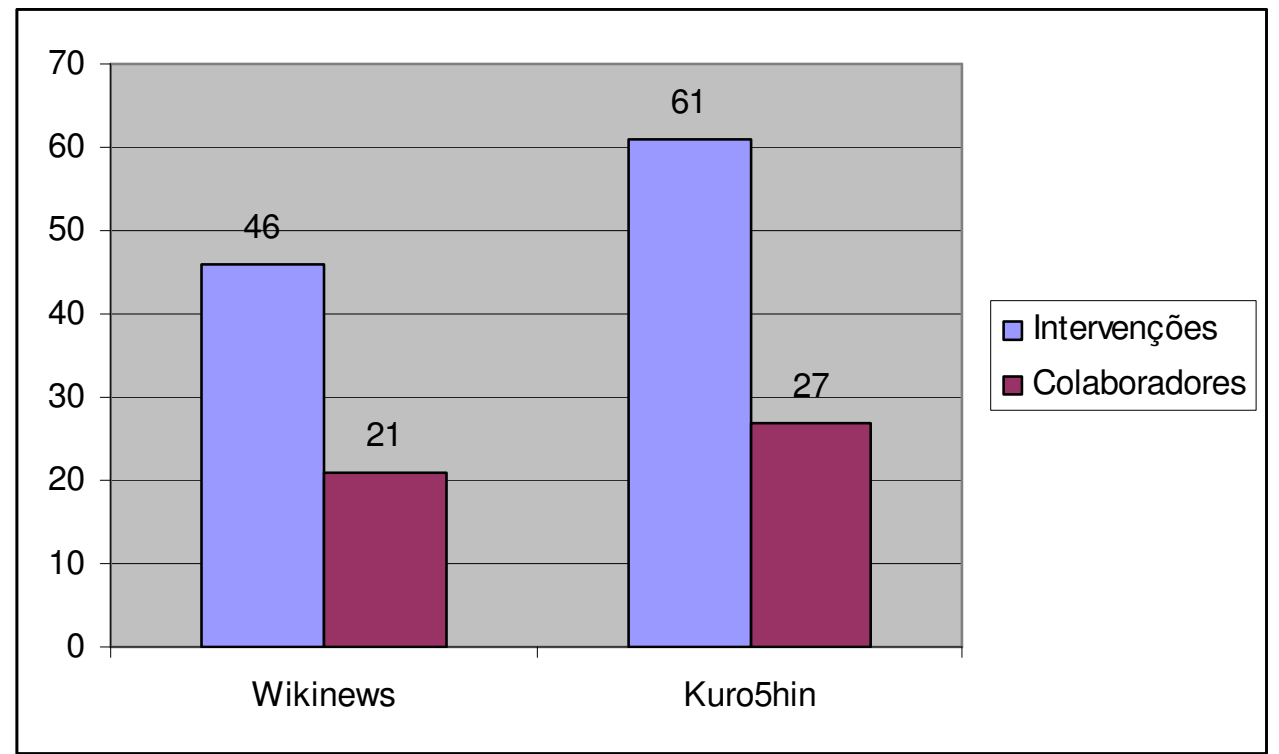

Figura 7 - Gráfico comparativo do número total de intervenções e número global de colaboradores

As 46 intervenções no $W N$ foram feitas por 21 colaboradores no total possivelmente menos, visto que 7 intervenções foram feitas por anônimos que podem ou não ter se repetido ${ }^{26}$. No caso do $K_{5}$ as intervenções anônimas são impossíveis, pode-se ter certeza de que 27 contas intervieram 61 vezes (embora um colaborador possa em tese operar mais de uma conta). A média de um colaborador para cada duas intervenções se mantém aqui, confirmando que a taxa de retorno é semelhante nos dois webjornais participativos. Esses dados também indicam que uma noção corrente a respeito de projetos que permitem a edição colaborativa de conteúdo editorial não se confirma. A saber, a idéia de que todo verbete ou notícia nesses serviços é escrita por dezenas de pessoas que acrescentam uma frase ou palavra cada uma. Não é "todo mundo" que participa no webjornalismo participativo, quando se examina o processo produtivo ao longo do tempo, mas um número relativamente fixo de colaboradores, que com isso adquirem experiência na operação das ferramentas e em reportagem.

Essa é uma constatação importante, visto que uma das principais críticas feitas a esse tipo de veículo é que os colaboradores escreveriam sem compromisso com o resultado final. A simples adição ocasional de uma frase em uma matéria do

26 Embora os IPs tenham sido registrados pelo sistema do WN e sejam todos diferentes, não é possível afirmar com certeza que se tratam de colaboradores diferentes. Quando se acessa a Internet através de um provedor, este atribui um novo IP a um determinado computador a cada novo acesso. Assim, uma mesma máquina pode ter um IP diferente a cada nova sessão de trabalho em que é conectada à rede. 
$W N$ ou a publicação de um comentário no $K_{5}$ por transeuntes ciberespaciais resultaria em uma cooperação fragmentada, em que nenhum dos colaboradores se veria como responsável pelo texto. Porém, se os colaboradores costumam retornar e acompanhar o desenvolvimento das matérias, certamente têm algum aprendizado através da experiência. Ver comentários apontando as falhas e equívocos de interpretação em seus textos nos comentários no $K_{5}$ ou as correções feitas diretamente pelos outros interagentes no $W N$ permite ao colaborador introjetar a política editorial destes veículos, de maneira muito semelhante ao que ocorre nas redações profissionais.

\section{Conclusão}

O objetivo principal desta análise de conteúdo era evidenciar o caráter predominante nas intervenções feitas pelos colaboradores no Kuro5hin e no Wikinews. A partir dos resultados, pode-se afirmar com segurança que predomina o caráter pluralizante, isto é, os colaboradores buscam em sua maioria acrescentar informações importantes aos textos iniciais sobre os quais atuam - mesmo quando o fazem de forma equivocada. Por outro lado, ao contrário do que se poderia esperar de webjornais participativos em que a publicação é totalmente aberta e autogerida, beirando a anarquia (em sentido estrito), não se verificou a presença expressiva de spam ou vandalismo.

A diferença nos números de intervenções entre os dois webjornais mostra que não existe apenas um modelo para esse tipo de iniciativa. Nesta pesquisa, dois deles foram abordados: um sistema em que a publicação é totalmente aberta, mas em que se busca o relato equilibrado dos fatos, idealmente sem interferência direta da subjetividade do colaborador, e outro em que há um controle da publicação, ainda que coletivo, e a valorização da opinião e da subjetividade. A análise da intervenção em outros webjornais participativos talvez resultasse em distribuições diferentes de unidades, conforme as políticas editoriais e as ferramentas disponíveis. Salta à vista, entretanto, o fato de que a proporção de intervenções pluralizantes foi semelhante no K5 e no $W N$, variando de $60 \%$ a $75 \%$ aproximadamente. Esse dado sugere que a tendência à cooperação é constante nos diferentes tipos de webjornal participativo e permite concluir que as pessoas estão dispostas a tomar parte na dinâmica noticiosa 
de maneira construtiva. As previsões apocalípticas sobre a instauração do caos comunicativo quando todo indivíduo pode publicar suas opiniões e relatos sem controle algum devem então, ao menos no que tange ao webjornalismo participativo, ser deixadas de lado.

Outro aspecto importante desse resultado é o fato de os colaboradores tenderem a acompanhar o desenvolvimento das matérias nas quais intervém. Por um lado, isso sugere a existência de um sentimento de responsabilidade pelo que é publicado. Por outro, sabe-se que as pressões e jogos de poder a que um repórter é submetido na redação incentivam a introjeção do ideário profissional do jornalismo, sobretudo os valores de imparcialidade e objetividade (BREED, 1993; SOLOSKI, 1993). Através das sanções impostas pela rede de colaboradores em cada webjornal participativo, acredita-se que os ideais e valores específicos a cada veículo são introjetados e ao mesmo tempo criados em conjunto, pela própria dinâmica da interação, de forma semelhante ao que ocorre nas redações profissionais.

Defende-se aqui, então, que os colaboradores de webjornais participativos têm pela experiência prática a possibilidade de aprender algumas técnicas e introjetar alguns valores que lhes permitam produzir material com certos traços jornalísticos, e que adquirem credibilidade ao longo do tempo - ou são desacreditados por seus erros. Isso coloca o público em uma posição de produtor e mediador de informação, papel que era restrito a jornalistas e outros profissionais de comunicação nos mídia tradicionais. Essa ampliação do papel do público é importante, porque permite a pluralização das perspectivas sobre os fatos na Web, na forma de webjornais participativos, blogs, ou seções de portais e webjornais em que a divisão entre profissional e amador se torna cada vez mais indistinguível. Isso não significa, porém, que se defenda aqui o fim do jornalismo. Muito pelo contrário: há a certeza de que o jornalismo profissional tem e terá um papel importante nas sociedades democráticas, na medida em que, através da manutenção da objetividade, pode reclamar imparcialidade e assim oferecer uma versão "oficial” dos fatos.

O webjornalismo participativo é portanto complementar, e não um substituto do jornalismo. Por outro lado, em sendo um complemento ao jornalismo tradicional, não se pode exigir do webjornalismo participativo a observação das mesmas regras - nem o mesmo gênero de credibilidade do jornalismo profissional, 
evidentemente. Se é esperado do consumidor de jornais, webjornais, programas de televisão e rádio um espírito crítico frente às notícias, o leitor de materiais publicados em webjornais participativos deve ter o dobro de cautela, já que os controles sobre a publicação são menos rígidos. Desprezar o conteúdo criado cooperativamente por leigos para poupar a sociedade dos "perigos" oferecidos pela publicação sem controle profissional é uma atitude paternalista, que dá muito pouco crédito à inteligência do público.

\section{Referências Bibliográficas}

BLOOD, Rebecca. Introduction. In: We've got blog!: how weblogs are changing our culture. Cambridge: Perseus, 2002.

BRAMBILLA, Ana Maria. Jornalismo open source: discussão e experimentação do OhmyNews International. Porto Alegre, 2006. Dissertação (Mestrado em Comunicação e Informação). Faculdade de Biblioteconomia e Comunicação, Universidade Federal do Rio Grande do Sul, Porto Alegre, 2006.

BREED, Warren. Controle social na redação: uma análise funcional. In: TRAQUINA, Nelson. Jornalismo: questões, teorias e "estórias”. Lisboa: Vega, 1993.

GILLMOR, Dan. We, the media: grassroots journalism by the people, for the people. Sebastopol: O'Reilly, 2004.

LAGE, Nilson. A estrutura da notícia. São Paulo: Ática, 1993.

MELO, José Marques de. Jornalismo opinativo: gêneros opinativos no jornalismo brasileiro. Campos do Jordão: Mantiqueira, 2003.

PEW Internet \& American Life Project. Bloggers: a portrait of the Internets new storytellers. 19/7/2006. Disponível em:

http://www.pewinternet.org/pdfs/PIP\%20Bloggers\%20Report\%20July\%201 9\%202006.pdf. Último acesso em: 09/1/2007.

PRIMO, Alex; TRÄSEL, Marcelo. Webjornalismo participativo e a escrita coletiva de notícias. Contracampo, Niterói, v.14, $1^{\circ}$ semestre/2006. Disponível em: http://www6.ufrgs.br/limc/PDFs/webjornal.pdf. Último acesso em: 10/01/2007.

SANTAELLA, Lucia. Navegar no ciberespaço: o perfil cognitivo do leitor imersivo. São Paulo: Paulus, 2004.

SOLOSKI, John. O jornalismo e o profissionalismo: alguns constrangimentos no trabalho jornalístico. In: TRAQUINA, Nelson. Jornalismo: questões, teorias e "estórias". Lisboa: Vega, 1993. 
TRÄSEL, Marcelo. A pluralização no webjornalismo participativo: uma análise das intervenções no Wikinews e no Kuro5hin. Porto Alegre, 2007. Dissertação (Mestrado em Comunicação e Informação). Faculdade de Biblioteconomia e Comunicação, Universidade Federal do Rio Grande do Sul, Porto Alegre, 2007. Disponível em: http://www6.ufrgs.br/limc/ 